\title{
PEMANFAATAN CENDAWAN ENTOMOPATOGEN Beauveria bassiana (BALSAMO) VUILEMIN DALAM PENGENDALIAN HAMA TANAMAN
}

\author{
Yustina M. S. W. Pu'u \\ Program studi Agroekoteknologi Fakultas Pertanian Universitas Flores \\ yus_puu@yahoo.com
}

\section{SUMMARY}

\section{Exploiting of Cendawan of Entomopatogen Beauveria bassiana (Balsamo) Vuilemin in control of crop} pest

The using of synthetic pesticide in control of crop pest cause various of negative impact like resistance, resurgence, incidence of secondary pets, killing of natural enemy and is impure of environmental even death to human being and animal. One of the correct operation alternative to decrease the using of synthetic pesticide is biological control with exploiting of entomopatogen caiied Beauveria bassiana.

This Entomopatogen have an ability for infection of insect either through direct contact, and also inoculation of woof was given to target insect by produce the toxin so that insect body closed conidia and become hard like mummy. The ability is also influenced by the condition of environment especially temperature and dampness. B. bassiana has high patogenistas ability almost in all of insect. B.bassiana can depress the population of coffe powder H. hampei of Helopeltis spp equal to $76 \%$ and the other insect type. Application of $B$. bassiana don't generate death at other pest which good for (natural enemy) in nature.

Infection mushroom mechanism of entomopatogen $B$. bassiana in control of pest in field happened by direct contact, inoculation and also contamination with target pest insect and effective in controlling of various pest insect type. Its effectiveness is influenced by variety of isolate types, closeness of spore, quality of media grow, controlled pest type, age of satadia pest, application time, application frequency and environmental factor.

\section{Keywords : exploiting, Beauveria bassiana, biological control}

\section{PENDAHULUAN}

Organisme penganggu tanaman (OPT) merupakan salah satu masalah yang dihadapi dalam setiap kegiatan budidaya tanaman pertanian. Kehadiran OPT sering meresahkan petani, dimana terjadi penurunan produksi bahkan gaga! panen. Gangguan yang ditimbulkan biasanya dimulai sejak tanaman di lapang hingga penyimpanan. Salah satu organisme penganggu tanaman (OPT) yang potensial menurunkan produktivitas adalah dari golongan serangga.

Pengendalian serangga hama yang umum dilakukan petani hanya bertumpu pada penggunaan insektisida sintetik, karena berdasarkan pengalaman insektisida sintetik paling efektif serta praktis dalam mengendalikan hama. Menurut Oka (1995), pemanfaatan pestisida/insektisida sintetik yang beriebihan, terus menerus dan tidak terkontrol akan menimbulkan akibat negatif terhadap lingkungan seperti residu dalam tanah, air dan udara, terjadi akumulasi dalam jaringan organisme, menyebabkan kekebalan (resistensi) dan ledakan (resurjensi) hama, timbulnya hama sekunder, membunuh musuh alami dan makhluk lainnya yang bukan sasaran scrta menyebabkan berbagai penyakit dan kematian pada manusia. Menyadari dampak yang timbul dari pemanfaatan insektisida sintetik, maka berbagai penelitian dan pengkajian dilakukan oleh para peneliti untuk mencari alternatif pengendalian yang selektif dan efektif serta am an bagi manusia dan lingkungan. Oleh karena itu, perhatian pada alternatif pengendalian yang ramah lingkungan semakin besar sehingga dapat menurunkan penggunaan pestisida sintetis dan keseimbangan ekosistem tetap -terjaga. Salah satu teknik pengendalian yang sesuai dengan konsep diatas adalah pengendalian hayati.

Pengendalian hayati merupakan salah satu komponen pengendalian hama terpadu (PHT) yang sesuai untuk mendukung pertanian berkelanj.utan dan berwawasan lingkungan. PHT merupakan salah satu tindakan pengendalian yang lebih selektif (tidak merusak organisme yang berguna dan manusia) dan berwawasan lingkungan, karena memadukan semua tindakan pengendalian yang ada untuk mengatasi masalah OPT di lapang. Dalam prisnsip PHT, penggunaan pestisida dijadikan sebagai alternatif pengendalian yang terakhir dan digunakan apabila populasi OPT telah melampaui ambang batas ekonomi. Pengendalian hayati pada 
dasarnya adalah pemanfaatan dan penggunaan musuh alami untuk mengendalikan populasi hama yang merugikan. Musuh alami tersebut dapat berupa predator, parasitoid dan patogen.

Pemanfaatan musuh alami dari golongan patogen merupakan salah satu afternatif pengendalianyang aman bagi manusia, lingkungan dan pelestarian musuh alami lainnya. Patogen serangga (entomopatogen) yang berpeluang sebagai alternatif pengendalian hama masih membutuhkan beberapa perbaikan potensi, produksi dan formulasi, pemahaman yang tepat terhadap kemampuannya berintegrasi dengan sistem/ekosistem, kesesuaiannya dengan lingkungan serta komponen PHT lainnya serta dapat ditcrima oleh petani atau pengguna. Salah satu entomopatogen yang berpotensi dikembangkan sebagai alternatif pengendalian hama adalah cendawan Beauveria bassiana.

Cendawan entomopatogen Beauveria bassiana (Balsamo) Vuilemin merupakan salah satu cendawan yang sangat potensial dalam pengendalian beberapa spesies serangga hama. Cendawan ini dilaporkan sebagai agensia hayati yang sangat efektif mengendalikan sejumlah spesies serangga hama termasuk rayap, kutu putih, dan beberapa jenis kumbang. Beauveria bassiana dapat diisolasi secara alami dari pertanaman maupun dari tanah. Epizootiknya di alam sangat dipengaruhi oleh kondisi iklim, terutama membutuhkan lingkungan yang lembab dan hangat. Di beberapa Negara, cendawan ini telah digunakan sebagai agensia hayati pengendalian sejumlah serangga hama mulai dari tanaman pangan, hias, buah-buahan, sayuran, kacangkacangan, hortikultura, perkebunan, kehutanan hingga tanaman gurun pasir.

Di Indonesia hasii-hasil penelitian B. bassiana juga telah banyak dipublikasikan, terutama dari tanaman pangan untuk mengendalikan serangga hama kedelai (Riptortus linearis dan Spodoptcra Htura), walang sangit pada padi (Leptocoriza acuta), Plutella xytostella pada sayur-sayuran, hama bubuk buah kopi Helopeltis antonii, dan penggerek buah kakao. Untuk dapat dimanfaatkan secara optimal dalam pengendalian hama, maka perlu diketahui bagaimana mekanisme infeksi $B$. bassiana dan efektivitasnya dalam mengendalikan hama sasaran. Tulisan ini bertujuan untuk mengetahui mekanisme infeksi cendawan entomopatogen $B$. bassiana terhadap serangga hama di lapang dan keefektivan cendawan entomopatogen $B$. bassiana terhadap serangga hama di lapang.

\section{ULASAN}

Cendawan Entomopatogen B. bassiana

Menurut klasifikasinya, $B$. bassiana termasuk kfas Hypomycetes, ordo Hypocreales dari famili Clavicipitaceae (Hughes, 1971 dalam Soetopo dan Indrayani, 2007). Cendawan entomopatogen penyebab penyakit pada serangga ini pertama kali ditemukan oleh Agostino Bassi di Beauce, Perancis. Steinhaus, 1975 yang kemudian mengujinya pada ulat sutera (Bombyx mori). Penelitian tersebut bukan saja sebagai penemuan penyakit pertama pada serangga, tetapi juga yang pertama untuk binatang.

Cendawan $B$. bassiana juga dikenal sebagai penyakit white muscardine karena miselia dan konidia (spora) yang dihasilkan berwarna putih, bentuknya oval, dan tumbuh secara zig-zag pada konidiopornya (Gambar 1). Cendawan ini memiliki kisaran inang serangga yang sangat luas, meliputi ordo Lepidoptera, Coleoptera, dan Hemiptera. Selain itu, infeksinya juga sering ditemukan pada serangga-serangga Diptera maupun Hymenoptera, Sedangkan habitat tanamannya antara lain: kedelai, sayursayuran, kapas, jeruk, buah-buahan, tanaman hias, bingga tanaman-tanaman hutan.

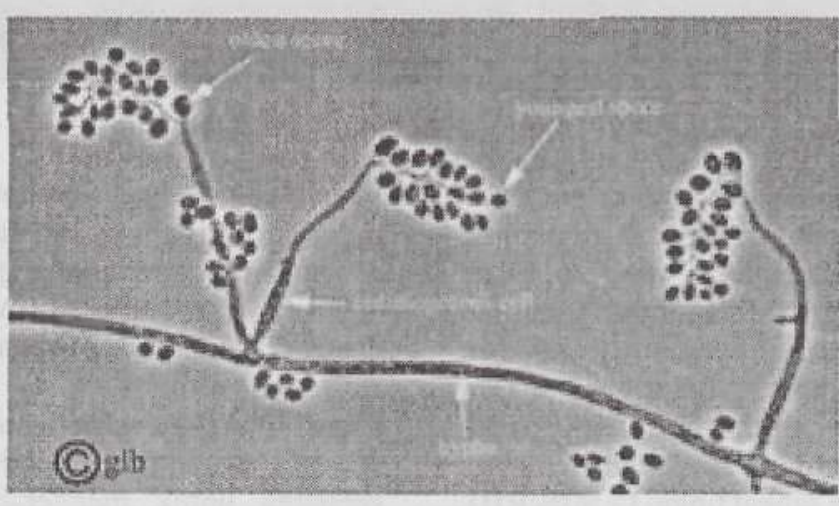

Gambar 1. Morfologi Beauveria bassiana

Mekanisme Infeksi $B$. bassiana

Mekanisme infeksi $B$. bassiana dimulai dari melekatnya konidia pada kutikula serangga, kemudian berkecambah dan tumbuh didalam tubuh inangnya. Perkecambahan konidia cendawan baik pada integumen serangga 
maupun pada media buatan umumnya, membutuhkan nutrisi tertentu, seperti glukosa, glukosamin, khitin, tepung, dan nitrogen terutama untuk pertumbuhan hifa. Beberapa strain isolat $B$. bassiana yang dikoleksi saat ini adalah berasai dari berbagai spesies serangga hama yang merupakan inang spesifiknya.

B. bassiana memproduksi toksin yang disebut beauvericin. Antibiotik ini dapat menyebabkan gangguan pada fungsi hemolimfa dan nukleus serangga, sehingga mengakibatkan pembengkakan yang disertai pengerasan pada serangga yang terinfeksi. Selain secara kontak, $B$. bassiana juga dapat menginfeksi serangga melalui inokulasi atau kontaininasi pakan. Broome et al. (1976) menyalakan bahwa $37 \%$ dari konidia $B$. bassiana yang dicampurkan ke dalam pakan semut api Selenopsis richteri, berkecambah di dalam saluran pencernaan inangnya dalam waktu 72 jam, sedangkan hifanya mampu menembus dinding usus antara 60-72 jam. Di dalam tubuh inangnya cendawan ini dengan cepat memperbanyak diri hingga seluruh jaringan serangga terinfeksi. Serangga yang telah terinfeksi, biasanya akan berhenti makan, menjadi lemah, dan kematiannya bisa lebih cepat. Kematian serangga biasanya disebabkan oleh kerusakan jaringan secara menyeluruh. Jumlah konidia yang dapat dihasilkan oleh satu serangga ditentukan oleh besar kecilnya ukuran serangga tersebut. Setiap serangga yang terinfeksi $B$. bassiana akan efektif menjadi sumber infeksi bagi serangga sehat di sekitarnya.

Cendawan $B$. bassiana keluar dari tubuh serangga yang terinfeksi mula-mula dari bagian alat tambahan (apendages) seperti antara segmensegmen antena, antara segmen kepala dengan toraks, antara segmen toraks dengan abdomen dan antara segmen abdomen dengan cauda (ekor). Setelah beberapa hari kcmudian seluruh permukaan tubuh serangga yang terinfeksi akan ditutupi oleh massa jamur yang berwarna putih (Gambar2). Penetrasi jamur entomopatogen sering terjadi pada membran antara kapsul kepala (head capsule) dengan toraks atau diantara segmensegmen apendages demikian pula miselium jamur keluar pertama kali pada bagian-bagian tersebut (Hasyimdkk,2009).

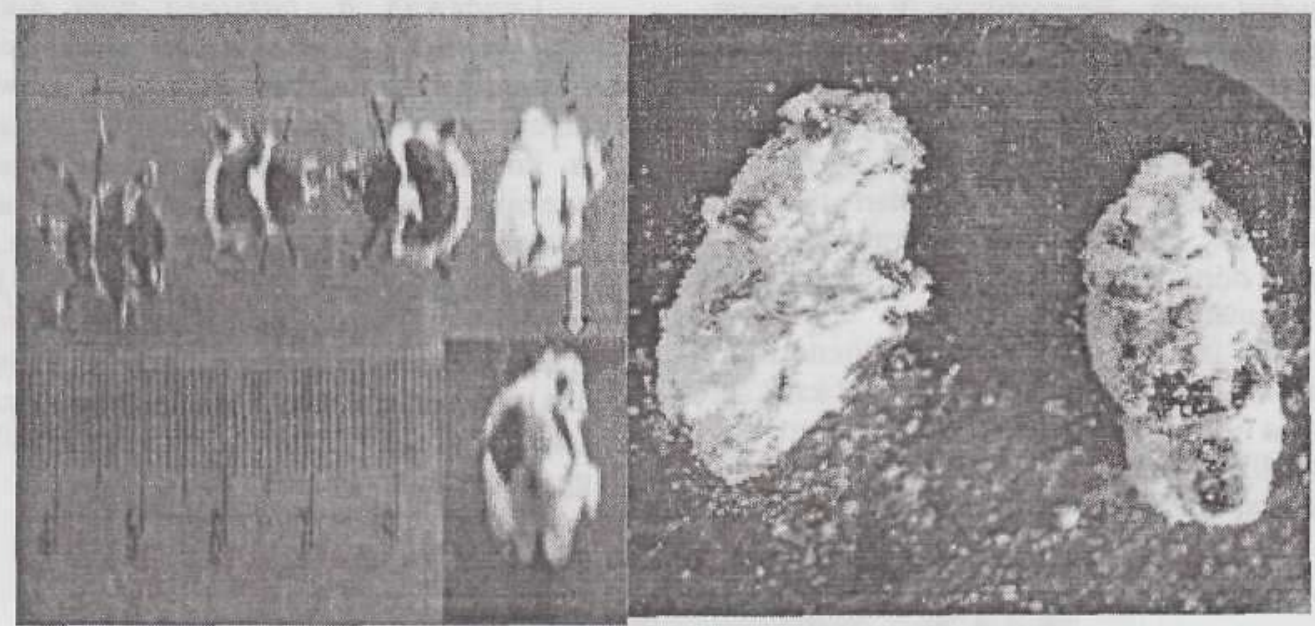

Gambar 2. Imago yang terinfeksi $\boldsymbol{B}$. bassiana

Faktor lingkungan, terutama kelembaban dan temperatur serta sedikit cahaya sangat penting perannya dalam proses infeksi dan sporulasi cendawan entomopatogen. Temperatur optimum untuk perkembangan, patogenisitas, dan kelulusan hidup cendawan umumnya antara 20-30 ${ }^{\circ} \mathrm{C}$. Untuk perkecambahan konidia dan sporulasi pada permukaan tubuh serangga dibutuhkan kelembaban sangat tinggi (> 90\% RH). Sebaliknya, untuk melepaskan konidia B. bassiana dari konidifor hanya dibutuhkan kelembaban sekitar 50\% (Soetopo dan Indrayani, 2007). Cahaya juga berpengaruh terhadap infeksi cendawan, dimana intensitas sinar ultraviolet dilaporkan dapat merusak konidia cendawan
Fuxa (1987) dalam Soetopo dan Indrayani (2007) menyatakan bahwa intensitas cahaya matahari dengan rata-rata panjang gelombang antara 290$400 \mathrm{~nm}$ cukup efektif menurunkan persistensi deposit konidia pada pertanaman.

Efektivitas Beauvenu bassiana

Keefektifan cendawan entomopatogen serangga untuk mengendalikan hama sasaran sangat tergantung pada keragaman jenis isolat, kerapatan spora, kualitas media tumbuh, jenis hama yang dikendalikan, umur stadia hama, waktu aplikasi, frekuensi aplikasi, dan faktor lingkungan meliputi sinar ultraviolet, curah hujan dan kelembaban (Widayat dan Rayati, 1993b). 
Cendawan entomopatogen mernbutuhkan lingkungan yang lembab untuk dapat menginfeksi serangga, oleh karena itu epizootiknya di alam biasanya terbentuk pada saat kondisi lingkungan lembab atau basah. Selain itu hams terjadi kontak antara spora $B$. bassiana yang diterbangkan angin atau terbawa air dengan serangga inang agar terjadi infeksi.

Konidia yang diaplikasikan dapat berupa suspensi, formulasi butiran, dan berbentuk pellet serta ketiganya menunjukkan hasil pengendalian yang cukup nyata. Beberapa hasil penelitian menyatakan bahwa aplikasi konidia $B$. bassiana dengan cara disemprotkan pada permukaan tanah, sangat efektif menyebabkan mortalitas hama sasaran. Hasil penelitian membuktikan bahwa sinar ultraviolet merupakan faktor abiotik yang paling menghambat aktivitas konidia di lapang, karena mempersingkat persistensinya pada permukaan tanah. Untuk mempertahankan efektivitas $B$. bassiana dan meningkatkan hasil pengendalian lapang adalah dengan melakukan aplikasi pada sore hari dan mempertinggi frekuensi aplikasi. Curah hujan sangat potensiai mengurangi jumlah konidia dari permukaan daun akibat hanyut terbawa air hujan.

\section{Keamanan hayati $B$. Bassiana}

Beberapa senyawa metabolit sekunder diproduksi oleh $B$. bassiana, seperti beauvericin, bassianin, bassiacridin, bassianolide, beauverolides, tenellin, dan oosporein. Senyawa metabolit sekunder ini dapat dihasilkan oleh $B$. bassiana pada epizootik di alam (tanah) maupun epizootik buatan (di laboratorium). Meskipun demikian, hingga saat ini belum ada laporan tentang terceraarnya rantai makanan oleh senyawa metabolit sekunder atau terakumulasi di aiam sebagai limbah epizootik $B$. bassiana. Hasil uji toksikologi terhadap salah satu produk $B$. bassiana Botanigard, menunjukkan bahwa produk tersebut tidak menimbuikan dampak negatif yang berhubungan dengan patogenisitas dan toksisitasnya, sehingga produk tersebut digunakan secara aman selama lebih dari 10 tahun di Amerika Serikat dan juga di beberapa negaralain.

Daiam bubungannya dengan keamanan secara hayati, cendawan entomopatogen dikelompokkan menjadi cendawan dengan kisaran inang spesifik dan kisaran inang luas. Cendawan yang memiliki kisaran inang spesifik umumnya menjadi parasit sejati (obligat) dan bersifat sangat virulen terhadap inang. Sebaliknya yang memiliki kisaran inang luas sebagian besar merupakan patogen fakultatif, bersifat saprofit, dan cenderung kuat patogenik, serta vimlensinya tinggi hanya pada spesies inang dari mana cendawan tersebut pertama kali diisolasi. Contoh, B. bassiana yang diisolasi dari ulat $H$. armigera akan lebih patogenik pada inangnya tersebut dibanding dengan inanginangnya yang lain. Dengan demikian, aplikasi $B$. bassiana di lapang cenderung aman bagi musuh alami atau serangga berguna lainnya.

Teknologiperbanyakan.fi. Bassiana

Perbanyakan $B$. bassiana sebagian besar dilakukan pada media padat, seperti beras, gandum, atau jagung (Sulistyowati, dkk., 2002). Pada tahap awal pengembangan, dibutuhkan inokulum cendawan dalam jumlah yang cukup untuk pengujian di iaboratorium dan lapang. Untuk kebutuhan tersebut, perbanyakan isolat $B$. bassiana cukup dilakukan pada media agar di dalam tabung reaksi. Sedangkan perbanyakan secara massal untuk komersial dapat dilakukan apabila telah terseleksi isolat-isolat yang paling virulen terhadap hama sasaran. Perbedaan genus atau spesies cendawan menyebabkan perbedaan kebutuhan akan nutrisi, $\mathrm{pH}$, kandungan air dalam media, tern per atur optimal untuk pertumbuhan, pembentukan konidia, cahaya, aerasi, dan periode inkubasi. Semua parameter tersebut hams dipertimbangkan dan dioptimalkan dalam perbanyakan B. bassiana, karena target tidak hanya pada efisiensi produksi, tetapi juga konidia yang dihasilkan harus berkualitas tinggi.

Media alami perbanyakan $B$. bassiana cukup tersedia, antara lain beras, gandum, kedelai roti dan kacang-kacangan. Tiga jenis bahan media alami yang telah dicoba dalam perbanyakan $B$. bassiana pada skala besar di New Zealand adalah beras, gandum dan barley. Hasilnya, beras merupakan media paling sesuai bagi perkembangan $B$. bassiana dengan produktivitas konidia tertinggi mencapai $4,38 \times 10^{9}$ konidia/g beras. Penggunaan berbagai jenis sereal, selain beras, sebagai media perbanyakan $B$. bassiana " perlu dipertimbangkan mengingat kandungan nutrisinya yang sangat bervariasi. Perbedaan kandungan nutrisi sangat mempengaruhi produksi konidia, terutama per kelompok produksi. Oleh karena itu, pemilihan bahan media perbanyakan harus dilakukan secara cepat, terutama memilih bahan yang memiliki kemampuan produksi konidia secara konsisten dalam kelompok-kelompok produksi. Hasil penelitian lain juga membuktikan bahwa beras putih merupakan bahan media perbanyakan $B$. bassiana yang tepat karena produksi konidiayangtinggi.

Temperatur inkubasi dan cahaya juga sangat menentukan produktivitas dari konidia. Temperatur optimal setiap cendawan bervariasi. Temperatur optimal untuk perkecambahan 
konidia adalah 25-30 ${ }^{\circ} \mathrm{C}$, dengan temperatur minimum $10^{\circ} \mathrm{C}$ dan maksimum $32^{\circ} \mathrm{C}$. Sedangkan $\mathrm{pH}$ optimal untuk pertumbuhan adalah 5,7-5,9, tetapi idealnya $\mathrm{pH}$ 7-8. Penelitian terdahulu membuktikan bahwa $B$. bassiana yang diproduksi di lingkungan tanpa cahaya (gelap) konidianya cenderung berukuran lebih besar dan lebih virulen dibanding yang diproduksi pada tempat terang. Hal ini penting sebagai bahan pertimbangan dalam memilih kemasan yang sesuai apabila biakan cendawan harus dibawa ke luar areal perbanyakan. Selain itu yang lebih penting dalam perbanyakan $B$. bassiana untuk skala komersial adalah kesesuaian produk dengan teknik formulasi dan aplikasinya. Umumnya produk $B$. bassiana diformulasi dalam bentuk bubuk (powder) dan merupakan formulasi paling efektif kontak dengan harna sasaran.

\section{Pemanfaatan dan Kendala Pengembangan B. bassiana}

Cendawan B. bassiana telah dimanfaatkan secara luas di selumh dunia untuk mengendalikan berbagai spesies serangga hama. Perkembangan pemanfaatannya semakin luas pada berbagai komoditas dan ekosistem, mulai dari tanaman hias, pangan, hortikultura, perkebunan dan tanaman gurunpasir.

Di Cina Penggunaan B. bassiana telah dirintis sejak tahun 1960 untuk mengendalikan berbagai serangga hama, sedangkan di Rusia digunakan untuk mengendalikan kumbang Colorado pada kentang. Di Kanada, Todoravaet et al (2003) dalam Soetopo dan Indrayani (2007), membuktikan bahwa isolat-isolat $B$. bassiana sangat efektif membunuh hama pengulung daun Choristoneura msaceana Harris (Lepidoptera: Totricidae). Kematian pada larva dan pupa mencapai lebih $85 \%$ pada dosis $10 \%$ konidia $/ \mathrm{ml}$ hingga 60 hari setelah perlakuan. Selain itu, pengaruh perlakuan juga menyebabkan gangguan pertumbuhan pada larva dan menurunkan persentase terjadinya imago jantan.

Di Indonesia, pengembangan penggunaan B. bassiana dalam pengendalian hama juga cukup pesat. Penelitian ujipotensi dan efektivitas baik di laboratorium maupun lapang juga telah dilakukan. Efektivitas $B$. bassiana juga telah diuji terhadap hama kelapa Bruntispa tongissima. Populasi hama bubuk buah kopi Hypothenemus hampei dan penggerek buah kakao Helopeltis spp. Sangat efektif dikendalikan hanya dengan tiga kali aplikasi $2,5 \mathrm{~kg}$ biakkan padat $B$. bassiana, dapat menekan serangan hingga $87 \%$ dan menurunkan populasi $76 \%$. Pada tanaman kapas, hasil pengujian di laboratorium menunjukkan bahwa terdapat dua isolat $B$, bassiana yang cukup efektif menyebabkan mortalitas pada ulat penggerek buah Helicoverpa armigera, yaitu isoiat BdEdlO yang masingmasing diisolasi dari imago Scotytidae pada kopi dan imago sejenis thrips dan diperbanyak pada $H$. armigera. Selain itu, B. bassiana juga efektif mengendalikan hama kepik renda lada pada tanaman lada Diconocoris hewetti DIST. Dimana, cendawan ini dapat mematikan imago $D$. hewetti pada konsentrasi 5 - $10 \mathrm{~g} / 1$ dengan tingkat kematian berkisar antara 75,50 - 97,50\% di lapang (Trisawa dan Laba, 2006).

Dukungan ekosistem dan faktor abiotik (kelembababan dan temperatur) yang ideal merupakan modal awal upaya pengembangan $B$. bassiana. Selain faktor lingkungan, pengetahuan yang berkaitan dengan $B$. bassiana sebagai agen hayati termasuk faktor-faktor teknts seperti mekanisme infeksi, kemampuan membunuh, durasi mematikan hama sasaran, dan teknik produksi dan penyimpanan juga perlu dipahami.

Prayogo (2006) dalam Soetopo dan Indrayani (2007) menyatakan bahwa, kendala pemanfaatan B. bassiana sebagai faktor mortalitas hama secara hayati antara lain disebabkan karena kurangnya pengetahuan petani tentang hama yang akan dikendalikan dan manfaat pengendalian, rendahnya pemahaman terhadap produk-produk hayati, dan kurang intensifnya sosialisasi produk kepada petani. Oleh karena itu, beberapa upaya yang perlu dilakukan untuk meningkatkan pemanfaatan $B$. bassiana dalam pengendalian serangga hama antara lain: (1) mendapatkan strain yang tepat, (2) meningkatkan virulensi dan kecepatan membunuh, (3) mempertinggi kesesuaiannya dengan kondisi lingkungan, (4) meningkatkan efisiensi produksi, (5) menyempurnakan formulasi agar mudah diaplikasikan, (6) meningkatkan persistensi dan masa infektifnya, (7) memahami secara benar interaksinya dengan lingkungan dan komponen PHT yang lain, (8) mempertimbangkan manfaat yang ditawarkan, klisusnya yang berkaitan dengan isu lingkungan, dan (9) dapat diterima oleh petani atau pengguna lainnya.

\section{SIMPULAN}

Berdasarkan uraian diatas, maka dapat disimpuikan beberapa hal yakni mekanisme infeksi cendawan entomopatogen $B$. bassiana dalam pengendalian hama di lapangan terjadi melalui kontak langsung, inokulasi serta kontaminasi dengan pakan serangga hama sasaran. Cendawan entomopatogen $B$. bassiana efektif dalam pengendalian berbagai jenis 
serangga hama yang dipengaruhi oleh keragaman jenis isoiat, kerapatan spora, kualitas media tumbuh, jenis hama yang dikendalikan, umur satedia hama, waktu aplikasi, frekuensi aplikasi dan faktor lingkungan.

\section{OAFTAR PUSTAKA}

Broome, J.R. 1974. Microbial Control of the Importd Fire ant, Solenopsis richteri (Forel) (Hymenoptera: Formicidae). M. S. Thesis, Mississipi State University, Starkville,MS.

Hasyim, A., Azwana, Mu'minin K. Cara mudah mendapatkan jamur Entomopatogen Beauveria bassiana dari tanah dengan teknik nmpan serangga http:/www.Balitbu.com

Hendromutarjo. 2008. Beauveria Bassiana Pengendali Hama Tanaman. http://fireant.tamu.edii/research/arr/Cat egorv/Non-chemical/90-91Pg44/9091Pg44.pdf

Irianti, A. T. P, Wagiman, FX, Martoredjo, T. 2001. Faktor-faktor yang mempengaruhi Patogenisitas Beauveria bassiana terhadap Bubuk Buah Kopi (Hypothenemus hampei). Agrosains 14 (3).

Oka, I. N. 1995. Pengendalian Hama Terpadu dan Implementasinya di Indonesia. Penerbit Gadjah Mada University Press.

Reintjes, C. B. Haverckort., A. water-Bayer. 1999. Pertanian Masa Depan. Pengantar untuk pertanian berkelanjutan dengan Input Luar Rendah.

Terjemahan dari: An Introduction to low-External Input and Sustainable Agriculture 1992 oleh Y. Sukoco, S.S. Kanisius. Yogyakarta.270p.

Sudarmadji, D., S. Gunawan. 1994. Patogenisitas Fungi Entomopatogen Beauveria bassiana terhadap Helopeltis antonii. Menara Perkebunan 62: 1 -5.

Sulistyowati, E., Y.D. Junianto, Sri-ukamto, S. Wiryadiputra, L. Winarto, dan N. Primawati. 2002. Analisis stats penelitian dan pengcmbangan PHT pada pertanaman kakao. Risalah Simposium Nasional Penelitian PHT Perkebunan Rakyat "Pengembangan dan Imp 1 ernentasi PHT Perkebunan Rakyat Berbasis Agribisnis", Bogor, 17-18 September 2002. Bagian Proyek PHT Perkebunan, Bogor. Him. 251264.

Wahyono, T. E. 2006. Pemanfaatan jamur patogen serangga dalam penanguiangan Helopeltis antonii danakibat serangannya pada jambu mete. Buletin Teknik Pertanian Vol. 11 No. 1

Trisawa, I. M., Laba, I. W. 2006. Keefektifan Beauveria bassiana dan Spicaria sp. Terhadap Kepik Renda Lada Diconocoris hewetti (DIST.) (Hemiptera:Tingidae). Buletin Litro Vol. XVII No. 2. Hal 99-106. http://balittro.litbang.dcptan.go.id/pdf/ biilletin/vol_xvii_noj)2_2006/vol_xvi i_no_02_2006_07.pdf

Soetopo, D., Indrayani Igaa. 2007. Status Teknologi dan Prospek Beauveria bassiana Untuk Pengendalian Serangga Hama Tanaman Perkebunan Yang Ramah Lingkungan, Balai Penelitian Tanaman Tembakau dan Serat. PrespektifVol.6No. I.Hal29-46. 